\title{
Knowledge and Practices of Personal Hygiene among Senior Secondary School Students of Ambassadors College, Ile- Ife, Nigeria
}

\author{
Article by Ilesanmi Oluwafemi Temitayo \\ Ph.D. in Public Health, Texila American University, Nigeria \\ E-mail: aboundinggrace08@yahoo.com
}

\begin{abstract}
Background: Personal hygiene deficiency diseases have been found to be a serious public health problem and people often affected are school children. These have been attributed to inadequate knowledge of personal hygiene and its practices.

Methods: This study is a cross- sectional study to investigate personal hygiene knowledge and practices of senior secondary school, Ile -Ife, Osun State, Nigeria. A pre-tested 25- item, purpose designed, self- administered questionnaires were used to collect information on knowledge and practices of the respondents on personal hygiene. Data were collated and analyzed based on descriptive study design.

Results: The result showed that the senior secondary school students who participated in the study were almost evenly distributed by gender (50.7\% males and 49.3\% females). Most of the respondents (50\%) were in the 12-14 year age bracket. The result also showed that majority of the respondents (98.2\%) had good knowledge of personal hygiene, could accurately identify the components and some of the harmful consequences of not engaging in sufficient personal hygiene practices. The result also showed that majority of the respondents had good hygienic practices including taking bath (99.6\%), brushing teeth (98.2\%) and washing hands (65.9\%).

Conclusion: Senior secondary school students of Ambassadors College, Ile- Ife have good personal hygiene knowledge and good personal hygiene practices.
\end{abstract}

Keywords: Personal hygiene, knowledge, practices

\section{Introduction}

Personal hygiene is an important global public health issue since long. Hygiene refers to practices associated with ensuring good health and cleanliness. Personal hygiene is the practice of maintaining cleanliness of ones own body. Good hygienic care as well as practices in terms of personal hygiene contributes to a large extent on factors relating to healthful living and prevention of hazards from diseases. These health risk factors are directly related to some important daily activities implicated with worthy operational actions and obligatory responsibilities, such as washing hands before meals and after defeacation with soap, brushing teeth at least twice a day specially after breakfast and after meals, taking bath with soap regularly, keeping nails short and taking regular exercise (Ali et al, 2013).

It is estimated that unsafe water, and lack of sanitation and hygiene every year claim lives of more than 1.5 million under five children from diarrhea (Mukherjee et al, 2014). Poor hygiene behaviour is a major problem in developing countries (Van Wijk et al, 2003). Hygiene and sanitation related diseases are a huge burden in developing countries; causing many people to fall ill even to die (UNICEF, 1998). A large fraction of the world's illness and death is attributable to communicable diseases. Sixty- two percent and 31\% of all deaths in Africa and Southeast Asia respectively are caused by infectious disease. This trend is especially notable in developing countries where acute respiratory and intestinal infections are the primary causes of morbidity and mortality among young children. Inadequate sanitary conditions and poor hygiene practices play major roles in the increased burden of communicable disease within these developing countries. The morbidities arising due to 
poor personal hygiene practices are more evident in the slum areas because of high population density, spread of respiratory infection, inadequate water supply, lack of sanitary facility, diarrhea and warm infestation, inadequate nutrition leading to anemia, malnutrition and vitamin deficiency (Raghava, 2005). Education must be provided to increase the level of knowledge. Schools are acknowledged as important places for developing health promotion and influencing health-related behaviours (Haaple et al, 2004; Moon et al, 1999; Sidebottom, 1995), including hygiene-related behaviours. Once habits are established in adolescence, they tend to be long-lasting and difficult to alter in adulthood (Wills et al, 2005). Thus, children educated in an effective way whilst at school may become adults who observe good hygiene practices. Knowledge influences people health. Through basic education and public knowledge individuals become aware of the meaning of self-protection and personal hygiene (Badran, 1995). Knowledge, attitude and practice of personal hygiene of school children have been found to increase significantly after education (Mukherjee et al, 2014; Biswas et al, 1990). In Nigeria, dental caries constitutes one of the major oral health problems with its prevalence being particularly high among young children and adolescents and the occurrence closely related to oral hygiene and socio economic class (Akpata, 2004). Adegbembo and El-Nadeef (1995) reported caries experience as high as 30 and 43\% among Nigerians aged 12 and 15 years, respectively.

There are many studies about the knowledge and practices of personal hygiene which were done on different groups (Tan et al, 2013; Miko et al, 2012; Suchitra et al, 2007). There are limited research findings to determine knowledge and practices of personal hygiene among secondary school students in Nigeria. However, this study is, therefore, directed to investigate the knowledge and practice of personal hygiene of senior secondary school students of Ambassadors College, Ile Ife, Nigeria as a case sample.

\section{Significance of study}

There is need to assess the personal hygiene knowledge and practices of this target group because they are more likely to engage in practices that may be inimical to their health than other groups and thus make them susceptible to hygiene deficiency illnesses. Furthermore, assessing their basic knowledge is essential for developing an effective personal hygiene education programs. In addition, the findings from this study can also provide basic and useful information for policy formulation and strategic interventions on personal hygiene among school students. The outcome of this study will serve as a guide for further research in this area.

\section{Statement of problem}

Several studies have shown that poor personal hygiene contribute to cross transmission of microorganisms, gum infections, increased rate of infectious illnesses, incidence of food borne outbreaks and reproductive tract infections. These have been attributed to inadequate knowledge of personal hygiene and its practices. Personal hygiene deficiency diseases have been found to continue to be a serious public health problem in developing countries like Nigeria and people often affected are school children. Moreover, to the best of my knowledge, limited studies focused on young students have been found in the literature and there is no formal study conducted concerning personal hygiene knowledge of secondary school students in Ile- Ife, Nigeria. Therefore, this study is aimed at assessing personal hygiene knowledge and practices of these senior secondary school students.

\section{Research questions}

The major research questions for this study include the followings:

1. Do senior secondary school students of Ambassadors College in Ile-Ife know about personal hygiene?

2. Do senior secondary school students of Ambassadors College in Ile-Ife engage in personal hygiene practices? 


\section{Research objectives}

1. To assess the knowledge of the senior secondary school students of Ambassadors College, IleIfe on personal hygiene.

2. To assess the practices of the senior secondary school students of Ambassadors College, Ile- Ife on personal hygiene.

\section{Literature review}

Personal hygiene is a concept that is commonly used in medical and public health practices. It involves maintaining the cleanliness of our body and clothes. It is personal. It is defined as a condition promoting sanitary practices to self. The knowledge and practice of personal hygiene are vital in all our everyday activities. The public health purposes of personal hygiene include the prevention of faeco-orally transmitted diseases, aesthetic values and social impact (Bastos, 2010). The components of personal hygiene include body hygiene (skin care), oral hygiene (oral care), hand washing (hand care), face hygiene, fingernail and toe nail hygiene (nail care), ear hygiene, hair hygiene, foot hygiene, arm pit and bottom hygiene, clothes hygiene and menstrual hygiene. Several studies show that personal hygiene practices include: seeing a doctor, seeing a dentist, regularly washing (bathing or showering) of the body, regular hand washing, brushing and flossing of teeth, basic manicure and pedicure, feminine hygiene and healthy eating (Ali et al, 2013; Bastos, 2010). Body hygiene pertains to hygiene practices performed by an individual to care for ones bodily health and well being. It is achieved by using personal hygiene products including: soap, hair shampoo, hair conditioner, cotton swabs, deodorant, chapstick, cream, lotion, facial tissue, hair clippers, nail clippers, nail files, skin cleansers, razors, shaving cream, skin cream and toilet paper (Bastos, 2010). All these products are used to improve health and well being. Oral hygiene refers to the care of the mouth and the teeth. It is achieved by going to the dentist, brushing the teeth and flossing the teeth. Diseases or conditions associated with poor oral hygiene include tooth decay, gum infection and bad breath (OU, 2016). The hand is important in adolescents especially secondary school students because when not properly taken care of, can serve as a medium of transfer of harmful microorganisms not just to the individuals, but also from one individual to another. A number of infectious diseases can spread from one person to another by contaminated hands, particularly gastro intestinal infections and hepatitis. Hand hygiene is recognized as the leading measure to prevent cross-transmission of microorganisms (Boyce et al, 2002; Pittet et al, 2000). A proper hand hygiene can help prevent the spread of these organisms. Some forms of gastro-enteritis can cause serious complications, especially for young children, the elderly or those with a weakened immune system. A causal link between hand hygiene and rates of infectious illness has been established in the literature (Aiello et al, 2002). A recent meta-analysis of 30 hand hygiene studies found that improvements in hand washing reduced the incidence of upper respiratory tract infections by $21 \%$ and gastrointestinal illnesses by 31\% (Aiello et al, 2008). Hand hygiene significantly reduces illness-related absences in elementary school students by $26 \%$ (Nandrup- Bus, 2009). Deficiencies in hand hygiene have been associated with outbreaks of viral gastroenteritis (Moe et al, 2001), upper respiratory tract infections (White et al, 2005; White et al, 2003) and group B streptococcal colonization (Bliss et al, 2002) among college students. Although mortality and morbidity associated with viral respiratory and gastrointestinal illnesses among college students are relatively low, these infections contribute to absenteeism that may, in turn, affect academic productivity and performance (ACHA, 2011). It was reported that poor hand hygiene contributed to 42\% of food- borne outbreaks in the United States in the period of 1975- 1998 (Aycicek et al, 2004). Critical times for hand washing include after using the toilet, after cleaning a child, and before handling food (Nandrup- Bus, 2009; Scott et al, 2007). Menstrual hygiene deals with the special health care needs and requirements of women during monthly menstruation or menstrual cycle. These areas of special concern include choice of the best protection of feminine hygiene products; how often and when to change the feminine hygiene products; bathing care of the vulva and vagina as well as the supposed benefits of vagina douching at the end of each menstrual period (John Hopkins, 2008). 
Provisions for good menstrual hygiene include home- made remedies like pieces of cotton cloth which are either placed on a woman's undergarment or on a home- made belt that wraps around the waist. These cloths can be washed, dried and used again. Available commercial products for women's hygiene during menstruation include pads, tampons and cups (Paul, 2007). The practice of good menstrual hygiene reduces the incidence of reproductive tract infection (RTI). Thus, the consequences of RTIs are severe and may result in significant negative impact to a woman's health including chronic pelvic pain, dysmenorrhea (painful periods) and in severe cases infertility. Reproductive tract infections, which have become a silent epidemic that devastates women's lives is closely related to poor menstrual hygiene (Dasguptal et al, 2008; Ten, 2007). Menstrual hygiene and management will directly contribute to millennium development goal (MDG) - 2 on universal educations, MDG- 3 on gender equality and women empowerment (Ten, 2007). Poor knowledge and practice of, and attitudes to personal hygiene has negative consequences for a child's long term overall development (Scott et al, 2007).

Knowledge is defined as the capacity to acquire, retain and use information. It is also a mixture of comprehension, experience, discernment and skill (Dong, 2015). It is a complicated construction characterized by the structure and the content of the information stored in the memory (Dong, 2015). Practice is regarded as the application of rules and knowledge that leads to action (Dong, 2015).

\section{Methods}

\section{Research design, study area and population}

A descriptive cross sectional study was conducted on personal hygiene knowledge and practices of senior secondary school students of Ambassadors College, Ile- Ife, Osun State, Nigeria. The study was carried out in Ambassadors College, a well-known and reputable private secondary school in IleIfe town. Ile-Ife is an ancient city of Yoruba land situated in Osun State which is located in the SouthWestern part of Nigeria. The study population consisted of the secondary school students' boys and girls in the senior secondary school one, two and three (SSS1, SSS2, and SSS3) of the College.

\section{Data collection}

Information was collected from respondents by means of a pre-tested 25- item, purpose designed, self- administered anonymous questionnaire containing open and closed ended questions.

The questionnaire was divided into three major sections for ease of administration. Section A containing 5 items focused on demographic characteristics of respondents. Section B containing 11 items focused on questions on knowledge of the respondents about personal hygiene while section $\mathrm{C}$ containing 9 items focused on questions on practice of the respondents about personal hygiene.

\section{Sample size determination}

The minimum sample size was calculated using the Leslie and Kish formula for descriptive studies $\mathbf{N}=\mathbf{P}(\mathbf{1 - P}) \mathbf{Z}^{2} / \mathbf{D}^{2}$ where $\mathrm{N}$ is the minimum sample size needed; $\mathrm{D}$ is the level of error that can be tolerated ( 0.05 chance of error) and $\mathrm{P}$, the estimated proportion of personal hygiene knowledge among college students from a previous study (Bastos, 2010) was $80 \%$ i.e. $\mathrm{p}=0.80$. $\mathrm{Z}$ is the standard variation corresponding to confidence level. At confidence level of 95\%, Z=1.96.

Therefore, $\mathrm{N}=0.80(1-0.80) 1.96^{2} / 0.05^{2} \mathbf{N}=\mathbf{2 4 5 . 8 6}$. To give allowance for an anticipated nonresponse rate of $10 \%$ ( 25 respondents), the sample size was increased by 25 to make 271 respondents. A total of 280 questionnaires were then taken to the school to be distributed for the study.

\section{Sampling method}

A simple random sampling method was used to select students from senior classes (SSS1, SSS 2 and SSS 3) of a private secondary school in Ile-Ife with age ranges from $12-20$ years to participate in the study. Of the 280 questionnaires distributed, 276 (response rate of 99\%) were returned and used for the analysis. Each respondent was provided with an assurance of confidentiality of information he 
or she provides in the questionnaire.

\section{Data analysis}

The completed questionnaires were collated, analyzed and presented using descriptive statistics of simple percentages, frequency distribution, means and ranges where applicable.

\section{Results}

\section{Demographic characteristics of the study population}

A total number of 276 senior secondary school students of Ambassadors college participated in the study in which $50.7 \%$ of them were males and $49.3 \%$ were female. Majority of the respondents $(50 \%)$ were between the ages of 12 and 14 years. The result also showed that the percentage distribution of the students in their various classes were very close as we have $36.6 \%$ in SS1, 38.6\% in SS2 and $25.4 \%$ in SS3. Largest percentages of them were Christians (95.3\%) as shown by the result. The result also showed that largest percentages of them were Yoruba (93.5\%) as shown in table 1.

Table 1. Demographic Characteristics of the study population

\begin{tabular}{|l|l|l|}
\hline $\begin{array}{l}\text { Socio-demographic } \\
\text { characteristics }\end{array}$ & Frequency & Percentage \\
\hline Age & 138 & \\
12-14 years & 133 & 50.0 \\
15- 17 years & 5 & 48.2 \\
18-20 years & $\mathbf{2 7 6}$ & 1.8 \\
Total & & $\mathbf{1 0 0 . 0}$ \\
\hline Sex & 140 & \\
Male & 136 & 50.7 \\
Female & $\mathbf{2 7 6}$ & 49.3 \\
Total & & $\mathbf{1 0 0 . 0}$ \\
\hline Class & 101 & \\
SSS 1 & 105 & 36.6 \\
SSS 2 & 70 & 38.6 \\
SSS 3 & $\mathbf{2 7 6}$ & 25.4 \\
Total & & $\mathbf{1 0 0 . 0}$ \\
\hline Religion & 263 & \\
Christianity & 13 & 95.3 \\
Islam & 0 & 4.7 \\
Traditional & $\mathbf{2 7 6}$ & 0.0 \\
Total & & $\mathbf{1 0 0 . 0}$ \\
\hline Ethnic group & 258 & 93.5 \\
Yoruba & 9 & 3.3 \\
Ibo & 0 & 0.0 \\
Hausa & 7 & 2.5 \\
Others & 2 & 0.7 \\
Non response & $\mathbf{2 7 6}$ & $\mathbf{1 0 0 . 0}$ \\
Total & & \\
\hline
\end{tabular}

\section{Personal hygiene knowledge levels of the respondents}

The result showed in table 2 below that 270 (97.8\%) of the respondents had heard of the term 'personal hygiene'. School constituted the largest source of information about personal hygiene accounting for $46 \%$ of responses. Parents accounted for $43.5 \%$ followed by books $17.4 \%$. Friends, Churches and Mosques constituted the least accounting for $12.7 \%$ and $13 \%$ respectively. More than 
95\% of respondents responded true to personal hygiene as practices performed by individual to care for ones bodily health and well being through cleanliness. All the respondents responded true to personal hygiene includes cleanliness of the body and clothes. 99\% of respondents responded true to personal hygiene includes regular brushing and flossing of teeth. $98 \%$ of respondents responded true to personal hygiene includes regular and proper hand washing. $88 \%$ of respondents agreed that personal hygiene includes balanced rest and exercise. About $80 \%$ and $77 \%$ responded true to seeing a doctor and dentist respectively as part of personal hygiene. The percentage of knowledge of respondents about personal hygiene products is $98.7 \%$. The percentage of knowledge of respondents about disease or condition which could be caused or worsened by poor personal hygiene is $63.2 \%$.

Table 2. Distribution of personal hygiene knowledge of respondents

\begin{tabular}{|l|l|l|}
\hline Variable & Frequency & Percentage \\
\hline Have you ever heard about the & & \\
term “personal hygiene”? & & \\
YES & 270 & 97.8 \\
NO & 6 & 2.2 \\
Total & $\mathbf{2 7 6}$ & $\mathbf{1 0 0 . 0}$ \\
\hline Where did you find out about & & \\
it? & & \\
School & 127 & 46.0 \\
Media & 46 & 16.7 \\
Books & 48 & 17.4 \\
Church/ Mosque & 36 & 13.0 \\
Friends & 35 & 12.7 \\
Parents & 120 & 43.5 \\
\hline Personal hygiene includes & & \\
practices performed by & & \\
individual to care for ones & & \\
bodily health and well being & & \\
through cleanliness? & & \\
TRUE & 271 & 98.2 \\
FALSE & 0 & 0.0 \\
NON RESPONSE & 5 & 1.8 \\
Total & $\mathbf{2 7 6}$ & $\mathbf{1 0 0 . 0}$ \\
\hline Personal hygiene includes & & \\
cleanliness of the body and & & \\
clothes? & & \\
TRUE & 276 & 100.0 \\
FALSE & 0 & 0.0 \\
Total & $\mathbf{2 7 6}$ & $\mathbf{1 0 0 . 0}$ \\
\hline Personal hygiene includes & & \\
regular brushing and flossing of & & \\
teeth? & & \\
TRUE & 274 & \\
FALSE & 1 & \\
NON RESPONSE & 1 & \\
Total & & \\
\hline Personal hygiene includes & & \\
regular and proper hand & & \\
washing? & & \\
& & \\
\hline
\end{tabular}




\begin{tabular}{|l|l|l|} 
TRUE & 270 & 97.8 \\
FALSE & 6 & 2.2 \\
Tot al & $\mathbf{2 7 6}$ & $\mathbf{1 0 0 . 0}$ \\
\hline Personal hygiene includes & & \\
balanced diet, rest and exercise? & & \\
TRUE & 244 & 88.4 \\
FALSE & 30 & 10.9 \\
NON RESPONSE & 2 & 0.7 \\
Tot al & $\mathbf{2 7 6}$ & $\mathbf{1 0 0 . 0}$ \\
\hline Personal hygiene includes & & \\
seeing a Doctor? & & \\
TRUE & 220 & 79.7 \\
FALSE & 53 & 19.2 \\
NON RESPONSE & 3 & 1.1 \\
Total & $\mathbf{2 7 6}$ & $\mathbf{1 0 0 . 0}$ \\
\hline Personal hygiene includes & & \\
seeing a Dentist? & & \\
TRUE & 213 & 77.2 \\
FALSE & 60 & 22.7 \\
NON RESPONSE & 3 & 1.1 \\
Total & $\mathbf{2 7 6}$ & $\mathbf{1 0 0 . 0}$ \\
\hline
\end{tabular}

\section{Personal hygiene practices level of the respondents}

The result showed in table 3 below that $99.6 \%$ of the respondents said they took a bath every day. $91.3 \%$ took a bath 1- 2 times daily whilst $6.9 \%$ had their baths 3- 4 times daily. $98.2 \%$ of respondents brushed their teeth daily. $93.8 \%$ brushed their teeth 1- 2 times daily while $4 \%$ brushed their teeth more than 2 times in a day. $46.4 \%$ of the respondents said they cut their nails weekly followed by 33\% which reported they cut their nails monthly. $65.9 \%$ of the respondents said they wash their hair daily followed by $14.1 \%$ which wash their hair monthly being females. About $47 \%$ and $46 \%$ responded they often see their doctor and dentist respectively in a year in the absence of illness. $91 \%$ of the respondents responded yes to eating balanced diet, exercise and rest well. The percentage of the practice of respondents about when do you wash your hands is $69.1 \%$. The percentage of the practice of respondents about the use of hygiene promoting products is $57.6 \%$.

Table 3. Distribution of personal hygiene practice level of respondents

\begin{tabular}{|l|l|l|}
\hline Variable & Frequency & Percentage \\
\hline $\begin{array}{l}\text { Do you take a bath } \\
\text { everyday? }\end{array}$ & & \\
YES & 275 & 99.6 \\
NO & 1 & 0.4 \\
Total & $\mathbf{2 7 6}$ & $\mathbf{1 0 0 . 0}$ \\
\hline How many times in a day? & & \\
1-2 TIMES & 252 & 91.3 \\
3- 4 TIMES & 19 & 6.9 \\
NON RESPONSE & 5 & 1.8 \\
Total & $\mathbf{2 7 6}$ & $\mathbf{1 0 0 . 0}$ \\
\hline $\begin{array}{l}\text { Do you brush your teeth } \\
\text { everyday? }\end{array}$ & & \\
YES & 271 & 98.2 \\
\hline
\end{tabular}




\begin{tabular}{|c|c|c|}
\hline $\begin{array}{l}\text { NO } \\
\text { NON RESPONSE } \\
\text { Total }\end{array}$ & $\begin{array}{l}3 \\
2 \\
276 \\
\end{array}$ & \begin{tabular}{|l|}
1.1 \\
0.7 \\
$\mathbf{1 0 0 . 0}$ \\
\end{tabular} \\
\hline $\begin{array}{l}\text { How many times in a day? } \\
\text { 1-2 TIMES } \\
\text { 3- } 4 \text { TIMES } \\
\text { NON RESPONSE } \\
\text { Total }\end{array}$ & $\begin{array}{l}259 \\
11 \\
6 \\
\mathbf{2 7 6} \\
\end{array}$ & \begin{tabular}{|l|}
93.8 \\
4.0 \\
2.2 \\
$\mathbf{1 0 0 . 0}$ \\
\end{tabular} \\
\hline $\begin{array}{l}\text { How often do you cut your } \\
\text { nails? } \\
\text { DAILY } \\
\text { WEEKLY } \\
\text { MONTHLY } \\
\text { RARELY } \\
\text { NON RESPONSE } \\
\text { Total }\end{array}$ & $\begin{array}{l}13 \\
128 \\
91 \\
10 \\
34 \\
\mathbf{2 7 6}\end{array}$ & \begin{tabular}{|l|}
4.7 \\
46.4 \\
33.0 \\
3.6 \\
12.3 \\
$\mathbf{1 0 0 . 0}$
\end{tabular} \\
\hline $\begin{array}{l}\text { How often do you wash } \\
\text { your hair? } \\
\text { DAILY } \\
\text { WEEKLY } \\
\text { MONTHLY } \\
\text { ONCE IN } 3 \text { MONTHS } \\
\text { NON RESPONSE } \\
\text { Total }\end{array}$ & $\begin{array}{l}182 \\
29 \\
39 \\
9 \\
17 \\
\mathbf{2 7 6}\end{array}$ & \begin{tabular}{|l|}
65.9 \\
10.5 \\
14.1 \\
3.3 \\
6.2 \\
$\mathbf{1 0 0 . 0}$
\end{tabular} \\
\hline $\begin{array}{l}\text { How often do you see your } \\
\text { Doctor in a year in the } \\
\text { absence of illness? } \\
\text { REGULARLY } \\
\text { NEVER } \\
\text { NON RESPONSE } \\
\text { Total }\end{array}$ & $\begin{array}{l}131 \\
110 \\
35 \\
\mathbf{2 7 6} \\
\end{array}$ & \begin{tabular}{|l|}
47.4 \\
39.9 \\
12.7 \\
$\mathbf{1 0 0 . 0}$ \\
\end{tabular} \\
\hline $\begin{array}{l}\text { How often do you see your } \\
\text { Dentist in a year in the } \\
\text { absence of illness? } \\
\text { REGULARLY } \\
\text { NEVER } \\
\text { NON RESPONSE } \\
\text { Total }\end{array}$ & $\begin{array}{l}128 \\
104 \\
44 \\
276\end{array}$ & \begin{tabular}{|l|}
46.4 \\
37.7 \\
15.9 \\
$\mathbf{1 0 0 . 0}$
\end{tabular} \\
\hline $\begin{array}{l}\text { Do you eat balanced diet, } \\
\text { exercise and rest? } \\
\text { YES } \\
\text { NO } \\
\text { NON RESPONSE } \\
\text { Total }\end{array}$ & $\begin{array}{l}251 \\
23 \\
2 \\
\mathbf{2 7 6} \\
\end{array}$ & \begin{tabular}{|l|}
91.0 \\
8.3 \\
0.7 \\
$\mathbf{1 0 0 . 0}$
\end{tabular} \\
\hline
\end{tabular}

\section{Discussion}

This study was conducted to assess the personal hygiene knowledge and practices of the senior secondary school students of Ambassadors College, Ile- Ife, Osun State, Nigeria. A total of 276 senior secondary school students were involved in this study. The largest percentage of the participants 
comes from the 12- 14 (50\%) years age group followed by the 15- 17 years age group which constituted $48.2 \%$ of the total respondents. Only $1.8 \%$ of the students were aged $18-20$ years. This is not surprising as most primary schools turn out most of their students from primary 5 when they age an average of about 10 years. There was an almost equal sex distribution with 140 (50.7\%) male respondents and 136 (49.3\%) female respondents. This is not unexpected also as the school is a coeducational school. The result also showed higher Christian respondents and Yoruba respondents than any other religions and tribes respectively. This result can be explained by the fact that the sampled private school is primarily a Christian college school located in Yoruba land. This invariably shows that the study environment will usually reflect the characteristics of the study population.

\section{Knowledge of respondents on personal hygiene}

Majority of the respondents (97.8\%) have heard about the term personal hygiene. This can be explained by the fact that the subject is taught in ancillary topics especially in primary school and junior secondary school in subjects like social studies and home economics. This further strengthened by the fact that majority of the respondents found out about it from school followed by parents with church, mosque and friends as the least source of information by the respondents. This result is supported by a similar study by Bastos (2010) and it shows that the concept of personal hygiene is not taken too seriously outside the confines of the academic environment. Majority of the respondents (98.2\%) agreed that personal hygiene includes all practices performed by an individual to care for ones bodily health and well being through cleanliness. The result obtained in this study is supported by a similar study of Bastos (2010) which showed that all the respondents agreed true to the definition of personal hygiene. In another similar study by Kumar et al, 2015, about $85.5 \%$ of the respondents knew correctly the meaning of personal hygiene. All the respondents agreed that personal hygiene includes cleanliness of the body and clothes. Almost all the participants (99.2\%) viewed regular brushing and flossing of teeth as part of personal hygiene. Majority of the respondents (97.8\%) viewed regular and proper hand washing as part of personal hygiene. Also, most of the respondents (88.4\%) responded true to personal hygiene including balanced diet, rest and exercise. This shows a good degree of knowledge among participants. This can be explained that most of these issues are covered in part of their curriculum at some point in time or other during the course of study. However, the level of knowledge dropped to about $79.7 \%$ and $77.2 \%$ when asked if personal hygiene involved seeing a doctor and a dentist respectively. The not too impressive degree of knowledge shown by the respondents on the issue of visiting a doctor or dentist as part of personal hygiene can be explained by the fact that hospitals and clinics are viewed as places to be visited by the sick and hence most individuals would not visit one except there is a pressing issue.

\section{Practices of respondents on personal hygiene}

Almost all the respondents (99.6\%) claimed to have their baths everyday with $6.9 \%$ of the total respondents having their bath 3- 4 times a day. In a similar study by Ali et al, 2013, 85.17\% were accustomed to taking their bath regularly. A similar result was obtained about oral hygiene with $98.2 \%$ brushing their teeth every day and 93.8\% of the respondents reported brushing their teeth 1- 2 times in a day. Approximately 69 percent of the study sample brushed their teeth at least twice daily in a study by Al- Wahadni et al, 2006. Those reporting tooth brushing with frequency of twice or more/day mounted toonly $24.5 \%$ ofthetotalstudents, significantly more among the caries free students (44.4\%versus $15.5 \%$ withcaries, $\mathrm{P}=0.001$ ) in a study by Amin et al, 2008. In another study by Talinova, 2008, $90 \%$ of the grammar school students replied they cleaned their teeth twice a day. This can be attributed to the fact that most of the respondents are teenagers and are likely to carry out these activities as they foster peer acceptance upon which outward appearance is based and which is also highly valued at this stage of their lives. Also, $46.4 \%$ of the respondents reported they cut their nails weekly. This result was supported by another study by Ghose et al, 2012 although slightly higher where $74.2 \%$ of the students were found trimming their nail once a week. Also in this study $65.9 \%$ of the respondents reported washing their hairs daily. The practice of the respondents about washing of 
hands is $69.1 \%$. This should be taken with a pinch of salt because as earlier stated most of the respondents agreed that hand washing is a part of proper personal hygiene, their attitude towards it was not commensurate to the degree of knowledge demonstrated hence the likelihood that this rate of hand washing is done only ceremoniously without paying heed to its real importance thereby making it ineffective. The percentage of the respondents who practiced seeing their doctors and their dentists regularly in the absence of illness were $47.4 \%$ and $46.4 \%$ respectively. The findings of this study was supported by a study by Ogundele et al, 2008 who reported that only few of the adolescents go for dental check up at least once a year. This result was in contrast to a study by Talinova, 2008 where 80 $\%$ of the grammar school students undergo regular dental examination at least twice per year. Also, $91 \%$ of the respondents practiced eating balanced diet, take exercise and rest. This was in contrast to a study by Ali et al, 2013 which reported that $91.53 \%$ of the respondents were not inclined to take exercise regularly.

\section{Limitation of the study}

This study is not without some limitations. One, the study is based on self- reported information and thus is subject to self- report bias. To correct this, effort was made to reduce the impact of this bias by making the questionnaire a guided self- administered process. Two, the students used for this study were drawn mainly from a private high school in Ile-Ife and therefore the outcome of the study cannot be generalized as they are not true representatives of all the secondary school students in IleIfe. Three, the number of respondents got from senior secondary school 3 (SSS3) were not up to those respondents in Senior Secondary School 1 and 2 because they were writing their final exams at the time of collecting the data and they were not readily available to fill the questionnaire.

\section{Conclusion}

The outcome of this study reveals that majority of the senior secondary school students considered in this study have good level of personal hygiene knowledge and a good number of them have high level of personal hygiene practices.

\section{Recommendation}

In view of the above conclusion, the followings are therefore recommended:

1. Attention should be given to the monitoring and evaluating personal hygiene practices among Ambassadors College students.

2. There is need for continuous educational programs to improve the personal hygiene practices of these students.

3. Personal hygiene knowledge and practices of these private college students can be compared with those in the public or rural secondary schools.

4. Personal hygiene knowledge and practices of students from other Colleges for the entire Ile- Ife town in a larger way can also be conducted.

\section{References}

[1]. Adegbembo, A.O., El- Nadeef, M.A.I (1995). National survey of periodontal status and treatment need among Nigerians. Int. Dent. J., 45: 197-203.

[2]. Aiello, A. E., Larson, E. L (2002). What is the evidence for a causal link between hygiene and infection? Lancet Infect Dis. 2: 103- 110.

[3]. Aiello, A. E., Larson, E. L (2002). Causal inference: the case of hygiene and health. Am J Infect Control. 60: 503- 510.

[4]. Aiello, A. E., Coulborn, R. M, Perez, E, Larson, E. L (2008). Effect of hand hygiene on infectious disease risk in the community setting: a meta- analysis. Am J Public Health.98: 1372- 81.

[5]. Ali, M.Y., Rahman, M.M., Siddiqui, M. H (2013). Exploring degree of awareness about healthcare and hygienic practices in Secondary School Students residing in semi- urban areas of Bangladesh. CBMJ. Vol 2, No 1.Pp 55- 62. 
[6]. Akpata, E.S. (2004). Oral health in Nigeria. Int. Dent. J., 53: 361-365.

[7]. Amin, T.T., Al- Abad, B.M (2008). Oral hygiene practices, dental knowledge, dietary habits and their relation to caries among male primary school children in Al Hassa, Saudi Arabia. International Journal of Dental Hygiene. 6(4): 361- 70. Doi: 10.1111/ j.1601- 5037. 2008. 00310.

[8]. Al- Wahadni, A.M., Al- Omri, M.K., Saeed, K.N (2006). Oral health attitudes, Knowledge, and Behaviour among School children in North Jordan. Journal of Dental Education. Vol. 70 No 2.Pp 179- 187.

[9]. American College Health Association (2011). American College Health Association- National College Health Assessment II: Reference Group Executive Summary fall 2010. American College Health Association; Lithicum.

[10]. AshrafulHayet, S. M., Hafizul Islam, M. D., Awal, M. A (2015).Knowledge of Oral Hygiene and Oral Health Status among the Secondary School Students. International Journal of Dental Medicine. 1(2): 17- 21. Doi: 10.11648/ j.ijdm.2015.0101.12.

[11]. Aycicek, H., Aydofan, H., Kucukkaraaslan, A., baysallar, M., Baousstaoflu, A. C (2004). Assessment of the bacterial contamination on hands of hospital food handlers. Food Control. 15 (4): 253- 259.

[12]. Badran, I.G (1995). Knowledge, attitude and practice: The three pillars of wisdom and excellence: A place in the medical profession. East. Mediter. Health J., 1: 8-16.

[13]. Bastos, T. S (2010). Personal hygiene, Knowledge, Attitude and Practice of Secondary School Students in Ikeja. https://www.scibd.com/doc/36903339.

[14]. Biswas, A.B., Roy, A.K., Das, K.K., San, A.K., Biswas, R (1990). A study of the impact of health education imparted to school children on their knowledge, attitude and practice in regard to personal hygiene. Ind J Pub Hlth. 34(2). 87- 92.

[15]. Bliss, S. J., Manning, S. D., Tallman, P., Baker, C. J., Paerlman, M. D., Marrs, C. F., et al (2002). Group B Streptococcus colonization in male and nonpregnant female university students: a cross sectional prevalence study.Clin Infect Dis. 34: 184- 90.

[16]. Boyce, J.M., Pittet, D (2002). "Guideline for hand hygiene in health-care settings. Recommendations of the healthcare infection control practices advisory committee and the HICPAC/SHEA/APIC/IDSA hand hygiene task force,” Morbidity and Mortality Weekly Report, vol. 23, no. 12, pp. S3-S40.

[17]. Carneiro, L., Kabulwa, M., Makyao, M., Mrosso, G., Choum, R (2011). Oral health knowledge and practices of secondary school students, Tanga, Tanzania.Int J Dent. Doi: 10.1155/ 2011/ 806258.

[18]. Dasgupta A, Sarkar M (2008). Menstrual hygiene: How hygienic is the adolescent girl? Indian J Community Med. 33(2):77-80.

[19]. Dong, T.T.M (2015).The knowledge, attitude, and practice of consumers towards food safety issues: A review of Taiwan. International Journal of Research Studies in Management 2015 October, Volume 4 Number 2, 13-22.

[20]. Ghose, J.K., Rahman, M.M, Hassan, J., Khan, M.S.R., Alam, A.A (2012). Microbes and Health. Vol 1 No 1.PP 34- 37.

[21]. Haaple, I., Probart, C (2004). Food safety knowledge, perceptions and behavior among middle school students. JNutr Educ Behaviour. 36: 71-6. Hygiene and environmental health module. A series on personal hygiene. The Open University. February, 2016.

[22]. John Hopkins, B (2008). The INFO project. Key facts about the menstrual cycle. School of Public Health, centre for communication program. http://www.Infoforhealth.Org/inforeports/menstruation.Pdf Comm. Med.33: 77- 80.

[23]. Kadi, A.A., Salati, S.A (2012). Hand hygiene practices among medical students. Interdiscip Perspect Infect Dis. Doi: 10. 1155/ 2012/ 679129.

[24]. Kumar, K.S., Akoijam, B.S (2015). Knowledge of personal hygiene and water borne diseases and practice of personal hygiene among students of central Agriculture University, Manipur, India. Int J Community Med Public Health. 2(4): 592- 595. Doi: 10. 18203/ 2394- 6040.ijcmph 20151053.

[25]. Miko, B.A., Cohen, B., Conway, L., Gilman, A., Seward, S.L., Larson, E (2012). Determinants of personal and household hygiene among college students in New York City, 2011.Am J Infect Control. 40(10). 940- 945. Doi: 10.1016/ j. Ajic. 2011.12.015. 
Texila International Journal of Public Health

Volume 4, Issue 4, Dec 2016

[26]. Moe, C. L, Christmas, W. A, Echols, L. J, Miller, S. E (2001). Outbreaks of acute gastroenteritis associated with Norwalk- like virus in campus setting. J Am Coll Health. 50: 57- 66.

[27]. Moon, A.M., Mullee, M.A., Thompson, R.L., Speller, V., Roderick, P (1999). Health-related research and evaluation in schools.Health Education. 1: 27-34. Nandrup-Bus, I (2009). Mandatory hand washing in elementary schools reduces absenteeism due to infectious illness among pupils: a pilot intervention study. Am J Infect Control. 37: 820-826. 10.1016/j.ajic.2009.06.012.

[28]. Ogundele, B.O., Ogunsile, S.E (2008). Dental health knowledge, attitude and practice on the occurrence of Dental caries among Adolescents in a Local Government Area (LGA) of Oyo State, Nigeria. Asian Journal of Epidemiology, 1: 64-71. Doi: 10.3923/ aje. 2008.64.71.

[29]. Paul D (2007). A report of an ICMR funded research project: Knowledge and practices of Adolescent girls regarding reproductive health with special emphasis on Hygiene during menstruation. New Delhi. National Institute of Public Cooperation and Child Development (NIPCCD).

[30]. Pittet, D., Hugonnet, S., Harbarth, S et al.(2000). "Effectiveness of a hospital-wide programme to improve compliance with hand hygiene,” The Lancet, vol. 356, no. 9238, pp. 1307-1312.

[31]. Raghava, P.K (2005). School Health. Ind. Jour. Of Com. Med. 30(4).

[32]. Scott, B. R. T., Curtis, V., Garbrah-Aidoo, N (2007). Health in our hands, but not in our heads: understanding hygiene motivation in Ghana. Health Policy Plan. 22 (4): 225-233. 10.1093/heapol/czm016.

[33]. Sidebottom, D (1995). School health education: do too many cooks spoil the broth? Health Education. 6: 17-23.

[34]. Suchitra, J.B., Devi, L.N (2007). Impact of education on knowledge, attitude and practices among various categories of health care workers on nosocomial infections. Indian Journal of Medical Microbiology. Volume 25.Issue 3.Pp 181- 187.

[35]. Talianova, M (2008). Attitude to and knowledge of oral hygiene of secondary school students. School and Health.21(3).Pp 199-209.

[36]. Tan, S.L., Cheng, P.L., Soon, H.K., Ghazali, H., Mahyudin, N.A (2013). A qualitative study on personal hygiene among food handlers at selected primary schools in Klang valley area, Selangor, Malaysia. International Food Research Journal. 20 (1): 71- 76.

[37]. Taylor, J.H., Brown, K.L., Toivenen, J., Holah, J.T (2000). A microbiological evaluation of warm hair driers with respect to hand hygiene and the washroom environment. Journal of Applied Microbiology. 89(6): 910- 919.

[38]. Ten VA (2007). Menstrual Hygiene: A Neglected Condition for the Achievement of Several Millennium Development Goals. Europe External policy Advisors.

[39]. UNICEF (1998). A manual on school sanitation and hygiene. Towards Better Programming Water, Environment and Sanitation Technical Guidelines. New York: UNICEF.

[40]. Van Wijk C., Tineke M (2003). Motivating Better Hygiene Behaviour. Importance for Public Heath Mechanisms of Change. Edited by: Steven E. The Hague, Netherlands: IRC International Water and Sanitation Centre.

[41]. White, C., Kolble, R., Carlson, R., Lipson, N (2005). The impact of a health campaign on hand hygiene and upper respiratory illness among college students living in residence halls. J Am Coll Health. 53: 175- 81.

[42]. White, C., Kolble, R., Carlson, R., Lipson, N., Dolan, M., Ali, Y et al (2003). The effect of hand hygiene on illness rates among students in university residence halls. Am J Infect Control. 31: 364- 70.

[43]. Wills, W., Backett-Milburn, K., Gregory, S., Lawton, J (2005). The influence of the secondary school setting on the food practices of young teenagers from disadvantaged backgrounds. Health Educ Res. 20: 458-65.

[44]. WHO: Water, sanitation and hygiene links to health; Facts and figures. 2004, Geneva: WHO. 